\title{
The predictive value of BOAH scale for screening obstructive sleep apnea in patients at a sleep clinic in Scotland
}

\author{
Agata Gabryelska ${ }^{1,2}$ (D) $\cdot$ Łukasz Mokros ${ }^{3} \cdot$ Grzegorz Kardas $^{4} \cdot$ Michał Panek $^{4} \cdot$ Renata Riha $^{2} \cdot$ Piotr Białasiewicz $^{1}$
}

Received: 22 November 2019 / Revised: 19 April 2020 / Accepted: 21 May 2020 / Published online: 10 June 2020

(C) The Author(s) 2020

\begin{abstract}
Objectives The study aimed to evaluate the diagnostic value of an original questionnaire for obstructive sleep apnea (OSA), the BOAH scale, and its ability to prioritize patients at high risk for OSA for polysomnography (PSG) examination.

Methods The analysis included 273 patients referred to the Department of Sleep Medicine of the Royal Infirmary, Edinburgh, Scotland. The BOAH scale is comprised of 5 parameters: BMI ( $\geq 30 \mathrm{~kg} / \mathrm{m}^{2}$ gives 1 point, $\geq 35 \mathrm{~kg} / \mathrm{m}^{2} 2$ points), presence of witnessed apneas during sleep ( 1 point), patient age $\geq 50$ years ( 1 point), and history of hypertension ( 1 point). Patients were divided into three study groups depending on OSA severity defined by the apnea-hypopnea index (AHI): at least mild (AHI $\geq 5$ ), at least moderate $(\mathrm{AHI} \geq 15)$, and severe $(\mathrm{AHI} \geq 30)$ OSA based on polysomnography examination.

Results In the group of patients with severe OSA, the best BOAH cutoff point was 4 points based upon the Youden index. With 4 points, the area under the receiver operating characteristic (ROC) curve was 0.778 (95\% CI $0.721-0.834$ ). Sensitivity and specificity were $57 \%$ and $89 \%$, respectively, yielding a positive and negative predictive value of $75 \%$ and $78 \%$, respectively, for diagnosis of severe OSAS in a patient sample with a pre-test probability for severe OSA at $37 \%$.

Conclusions The BOAH scale in this group of Scottish patients performed comparably to other available questionnaires and scales while being shorter and simpler. The findings suggest that the BOAH scale should be considered as a useful instrument in OSA diagnosis and prioritization of high-risk patients for PSG examination.
\end{abstract}

Keywords OSA $\cdot$ Predictive value $\cdot \mathrm{BOAH} \cdot \mathrm{PSG}$

\section{Introduction}

Obstructive sleep apnea (OSA) is a prevalent sleep disorder characterized by recurrent pauses in breathing during sleep

Abstract with larger group of participants (due to different inclusion criteria) and limited analysis compared to the manuscript was presented at 13th YES Meeting (Porto, Portugal; 13-16.09.2018)

Agata Gabryelska

agata.gabryelska@gmail.com

1 Department of Sleep Medicine and Metabolic Disorders, Medical University of Lodz, Mazowiecka 6/8, 92-215 Lodz, Poland

2 Department of Sleep Medicine, Royal Infirmary Edinburgh, Edinburgh, UK

3 Department of Clinical Pharmacology, Medical University of Lodz, Lodz, Poland

4 Department of Internal Medicine, Asthma and Allergy, Medical University of Lodz, Lodz, Poland caused by the collapse of upper airways. It is associated with metabolic and cardiovascular comorbidities [1]. The primary risk factor for OSA is obesity, which leads to an increased volume of pharyngeal soft tissue. It is estimated that $90 \%$ of patients suffering from OSA are overweight and over $60 \%$ is obese [2]. The important unmodifiable risk factors for OSA are age over 50 years and male sex [3]. The prevalence of the disorder in the general adult population currently ranges between 9 to $38 \%$ [4]. However, some studies estimate that at least a moderate form of OSA may affect up to $23 \%$ women and $49 \%$ of men [5].

The polysomnography (PSG) is considered as a gold standard in OSA diagnosis. Unfortunately, access to this diagnostic procedure is limited due to its cost and the low number of specialized diagnostic sleep clinics. Thus, there is a great need to develop a simple and effective questionnaire to assess the probability of OSA and prioritize patients at high risk for the diagnostic PSG. One of the most commonly used tools is the STOP-BANG questionnaire. It consists of four subjective parameters (STOP: snoring, tiredness, observed apnea, and 
history of arterial hypertension) and four demographic items (BANG: BMI, age, neck circumference, and gender) [6].

Other screening tests, including the Berlin questionnaire, STOP, Epworth sleepiness scale, and recently created NoSAS scale, are all used to identify high-risk patients [7, 8]. However, some of these tools are lengthy and complicated or require an upper airway assessment, making them inconvenient to use. Meta-analyses of different tools showed that the STOP-BANG questionnaire is the most accurate in OSA diagnosis [7]. However, recent studies suggest that NoSAS is a superior screening tool to detect clinically significant sleepdisordered breathing.

BOAH scale is a shortened version of the STOP-BANG questionnaire that consists of variables that can easily be assessed by a physician: BMI, a history of witnessed apneas during sleep, a patient's age, and a history of hypertension [9, 10]. Originally, the scale was created in Sleep and Respiratory Disorders Centre (Lodz, Poland), specializing in OSA diagnostics [9]. Therefore, the aim of this study was to assess the diagnostic value of this scale among patients referred to a sleep clinic due to diverse sleep disorders and examine its ability to prioritize patients with a high risk of OSA for PSG examination.

\section{Materials and methods}

The retrospective study involved 273 consecutive patients referred to the Department of Sleep Medicine of the Royal Infirmary (Edinburgh, Scotland) due to presumptive sleep disorder diagnosis between June 2015 and July 2016, who underwent diagnostic PSG examination. Based on data from patients' history and examination, a BOAH scale score was calculated based on the following scoring criteria: BMI $(\geq$ $35 \mathrm{~kg} / \mathrm{m}^{2}-2$ points, $\geq 30 \mathrm{~kg} / \mathrm{m}^{2}-1$ point), witnessed apneas during sleep ( 1 point), patient's age ( $\geq 50-1$ point) and a history of arterial hypertension (1 point).

\section{Polysomnography}

After the admission to the sleep laboratory $(21: 00 \mathrm{~h} \pm 0.5 \mathrm{~h})$ patients underwent body mass, height, heart rate, and blood pressure measurements. Following channels were used to record standard PSG: electroencephalography (C4\A1, C3\A2), chin muscles and anterior tibialis electromyography, electrooculography, measurements of oronasal airflow (a thermistor and cannula), snoring, body position, respiratory movements of chest and abdomen (plethysmographic belts), unipolar electrocardiogram, and hemoglobin oxygen saturation $\left(\mathrm{SaO}_{2}\right)$. Sleep stages were scored according to the criteria based on a $30 \mathrm{~s}$ epoch standard. Apnea was defined as a reduction of airflow to less than $10 \%$ of the baseline for at least $10 \mathrm{~s}$ while hypopnea as at least $30 \%$ reduction of airflow for at least $10 \mathrm{~s}$, co-occurring with decrease in $\mathrm{SaO}_{2}$ over $3 \%$ or an arousal. Electroencephalogram arousals were scored according to the American Academy of Sleep Medicine guidelines [11]. Additionally, PSG was extended by video recording of the patient while asleep.

All patients gave written informed consent for diagnostic polysomnography. The study was conducted in accordance with the amended Declaration of Helsinki.

\section{Statistical analysis}

The data were analyzed with the Statistica 13.1 software (StatSoft, Tulsa, USA). Data distribution was tested with the Shapiro-Wilk test. The Student's $t$ test or Mann Whitney $U$ was used to compare continuous variables in case of normal and non-normal distribution of data, respectively. The frequencies were compared with $\mathrm{Chi}^{2}$ test. Receiver operating characteristic (ROC) curves were created, and area under the

Table 1 Characteristics of the study groups

\begin{tabular}{llllll}
\hline & Study group & No OSA (AHI < 5) & $\begin{array}{l}\text { At least mild OSA } \\
(5 \leq \mathrm{AHI})\end{array}$ & $\begin{array}{l}\text { At least moderate OSA } \\
(15 \leq \mathrm{AHI})\end{array}$ & $\begin{array}{l}\text { Severe OSA } \\
(30 \leq \mathrm{AHI})\end{array}$ \\
\hline$N$ & 273 & 33 & 240 & 175 & 102 \\
Age (years) & $49.4 \pm 17.3$ & $41.4 \pm 13.9$ & $51.0 \pm 13.3$ & $52.0 \pm 12.3$ & $54.9 \pm 12.2$ \\
BMI $\left(\mathrm{kg} / \mathrm{m}^{2}\right)$ & $30.5(26.7-36.1)$ & $26.4(23.7-31.7)$ & $30.9(27.2-36.3)$ & $32.0(28.3-37.5)$ & $33.1(29.1-38.7)$ \\
AHI & $21.7(9.2-41.2)$ & $2.6(1.8-3.5)$ & $25.6(14.0-45.6)$ & $33.4(23.8-61.2)$ & $52.6(36.9-75.0)$ \\
Gender & $143 \mathrm{M}(52 \%)$ & $8 \mathrm{M}(24 \%)$ & $135 \mathrm{M}(56 \%)$ & $104 \mathrm{M}(59 \%)$ & $58 \mathrm{M}(57 \%)$ \\
Observed apneas & $171(62 \%)$ & $9(27 \%)$ & $162(68 \%)$ & $130(74 \%)$ & $80(78 \%)$ \\
Arterial hypertension & $110(40 \%)$ & $7(21 \%)$ & $103(43 \%)$ & $91(52 \%)$ & $70(69 \%)$ \\
BOAH score & $2(1-4)$ & $1(0-2)$ & $3(1-4)$ & $3(2-4)$ & $4(2-4)$ \\
\hline
\end{tabular}

Data are shown as mean \pm SD or median (IQR)

$A H I$ apnea-hypopnea index, $B M I$ body mass index, $M$ male, $O S A$ obstructive sleep apnea 
Table 2 Predictive values for all $\mathrm{BOAH}$ scores for OSA diagnosis

\begin{tabular}{|c|c|c|c|c|c|c|c|}
\hline OSA severity & Initial risk & $\begin{array}{l}\text { BOAH } \\
\text { score }\end{array}$ & $n$ & Sensitivity & Specificity & PPV & NPV \\
\hline \multirow[t]{6}{*}{ At least mild (AHI $\geq 5$ ) } & \multirow[t]{6}{*}{$88 \%$} & 0 & 25 & - & - & - & - \\
\hline & & 1 & 44 & $89 \%$ & $39 \%$ & $91 \%$ & $34 \%$ \\
\hline & & 2 & 47 & $71 \%$ & $70 \%$ & $94 \%$ & $25 \%$ \\
\hline & & 3 & 49 & $51 \%$ & $82 \%$ & $95 \%$ & $19 \%$ \\
\hline & & 4 & 56 & $31 \%$ & $94 \%$ & $97 \%$ & $16 \%$ \\
\hline & & 5 & 19 & $8 \%$ & $97 \%$ & $95 \%$ & $13 \%$ \\
\hline \multirow[t]{6}{*}{ At least moderate $(\mathrm{AHI} \geq 15)$} & \multirow[t]{6}{*}{$64 \%$} & 0 & 6 & - & - & - & - \\
\hline & & 1 & 29 & $97 \%$ & $33 \%$ & $72 \%$ & $84 \%$ \\
\hline & & 2 & 33 & $80 \%$ & $58 \%$ & $77 \%$ & $62 \%$ \\
\hline & & 3 & 39 & $61 \%$ & $77 \%$ & $82 \%$ & $52 \%$ \\
\hline & & 4 & 51 & $39 \%$ & $91 \%$ & $88 \%$ & $46 \%$ \\
\hline & & 5 & 17 & $9 \%$ & $97 \%$ & $84 \%$ & $38 \%$ \\
\hline \multirow[t]{6}{*}{ Severe $(\mathrm{AHI} \geq 30)$} & \multirow[t]{6}{*}{$37 \%$} & 0 & 1 & - & - & - & - \\
\hline & & 1 & 13 & $99 \%$ & $22 \%$ & $42 \%$ & $97 \%$ \\
\hline & & 2 & 15 & $86 \%$ & $46 \%$ & $48 \%$ & $85 \%$ \\
\hline & & 3 & 15 & $71 \%$ & $67 \%$ & $55 \%$ & $80 \%$ \\
\hline & & 4 & 43 & $57 \%$ & $89 \%$ & $75 \%$ & $78 \%$ \\
\hline & & 5 & 15 & $14 \%$ & $97 \%$ & $74 \%$ & $66 \%$ \\
\hline
\end{tabular}

$A H I$ apnea-hypopnea index, $N P V$ negative predictive value, $O S A$ obstructive sleep apnea, $P P V$ positive predictive value

curve (AUC) was calculated for $\mathrm{AHI} \geq 5, \geq 15$, and $\geq 30$ events/h using BOAH score as a predictor variable. Based on Youden index, cutoff points for the scale score were chosen. A value of $p<0.05$ was considered significant.

\section{Results}

Characteristics of the study group, including BOAH scores, are shown in Table 1.

The initial risk for at least mild OSA was $88 \%$, while for the severe $37 \%$. Sensitivity, specificity, positive predictive value (PPV), negative predictive value (NPV), and number of individuals for each BOAH score are showed in Table 2. BOAH score of 4 had PPV of $97 \%$ for at least mild and $88 \%$ for at least moderate form of OSA. Furthermore, the BOAH score of less than 2 had NPV of $97 \%$ for severe and $84 \%$ for at least moderate OSA, while score of less than 3 had NPV of $85 \%$ for severe OSA.

Based on Youden index, cutoff level of 4 points in BOAH scale was chosen for severe OSA, which resulted in sensitivity of $57 \%$, specificity of $89 \%$, positive predictive value (PPV) of $75 \%$, and negative predictive value (NPV) of $78 \%$. The AUC was the largest for severe OSA -0.776 (95\% CI 0.718-0.833) $(p<0.001)$. The ROC curves for BOAH scale in mild, moderate, and severe OSA are shown in Table 3 and Fig. 1.

\section{Discussion}

With a continuing increase in OSA prevalence and limited access to PSG examination it is important to prioritize patients with a higher risk for the severe form of the disorder. Multiple scales and questionnaires have been created to screen patients

Table 3 ROC curve attributes for BOAH scale in at least mild, moderate, and severe OSA groups

\begin{tabular}{lllllllllll}
\hline OSA severity & Pre-test probability & Cutoff point & Youden index & Sensitivity & Specificity & PPV & NPV & AUC & $95 \%$ CI & $p$ \\
\hline At least mild (AHI $\geq 5)$ & $88 \%$ & 2 & 0.41 & $71 \%$ & $70 \%$ & $94 \%$ & $25 \%$ & 0.749 & $0.660-0.838<0.001$ \\
At least moderate (AHI $\geq 15)$ & $64 \%$ & 2 & 0.38 & $80 \%$ & $58 \%$ & $77 \%$ & $62 \%$ & 0.764 & $0.704-0.823<0.001$ \\
Severe (AHI $\geq 30)$ & $37 \%$ & 4 & 0.46 & $57 \%$ & $89 \%$ & $75 \%$ & $78 \%$ & 0.778 & $0.721-0.834<0.001$ \\
\hline
\end{tabular}

$A H I$ apnea-hypopnea index, $A U C$ area under curve, $C I$ confidence interval, $N P V$ negative predictive value, $O S A$ obstructive sleep apnea, $P P V$ positive predictive value, $R O C$ receiver operating curve 
a

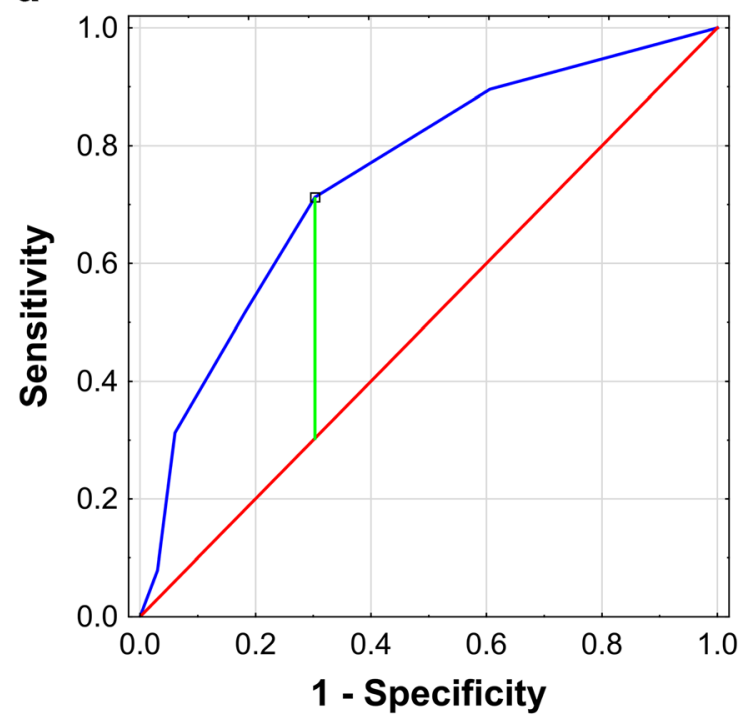

b

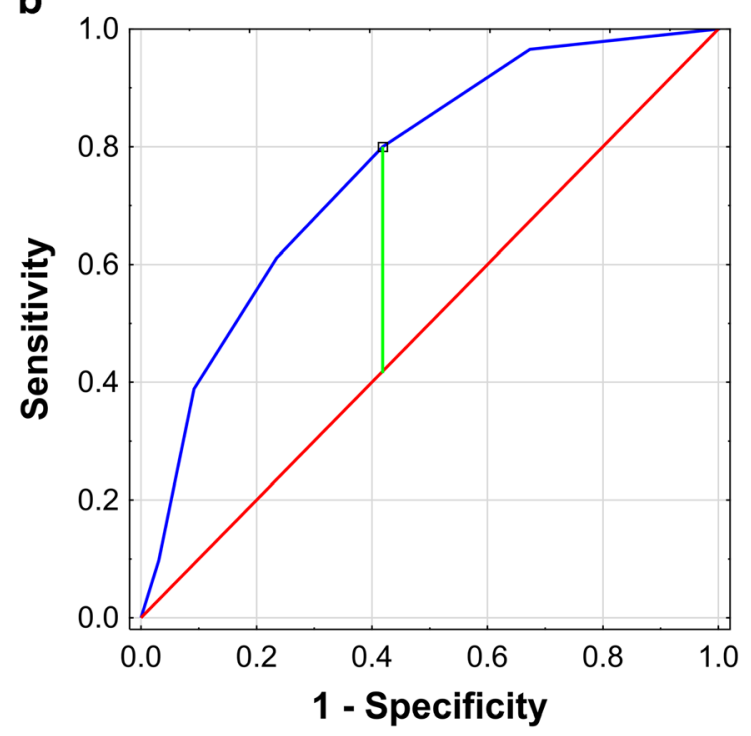

C

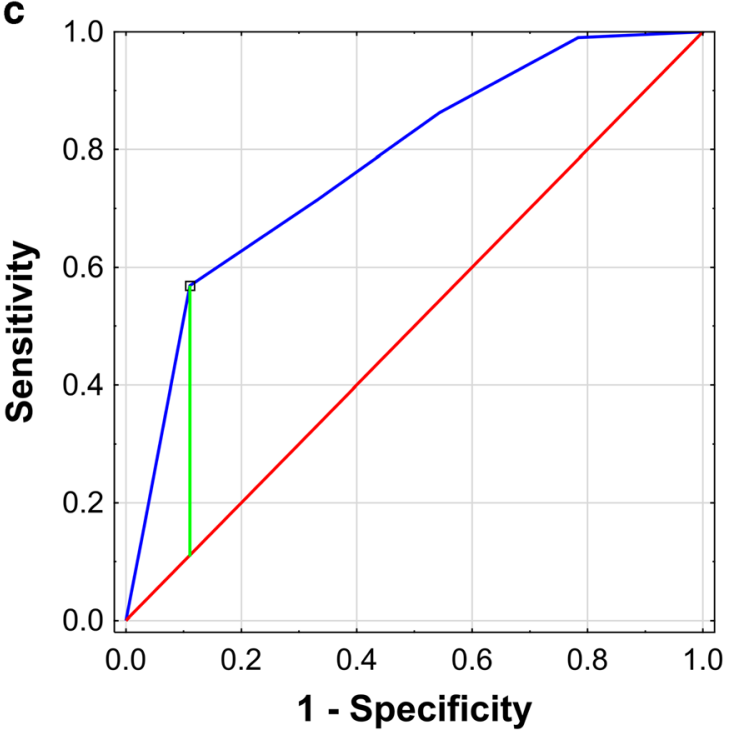

Fig. 1 ROC curves for BOAH scale in mild, moderate, and severe OSA. Receiver operating characteristic (ROC) curves for BOAH scale for: amild obstructive sleep apnea (OSA), b - moderate OSA, $\mathbf{c}$ - severe OSA

for OSA and refer them for PSG examination. Two of the most popular tools include the STOP-BANG questionnaire [12] and the recently developed NoSAS score [8]. However, both scales include either numerous parameters, 8 in the STOP-BANG questionnaire and multiple scoring levels for parameters in NoSAS. Newly created BOAH scale is one of the simplest tools available with only 4 variables and only BMI with 2 different levels of scoring. Additionally, 3 remaining variables: observed apneas, age over 50 , and history of hypertension are collectible at history taking, allowing for the calculation of BOAH score in a short time, making the tool more practical and convenient.

BOAH scale had greater diagnostic value compared to the STOP-BANG questionnaire in the meta-analysis, which at the optimal cutoff point of 5 for severe OSA had both specificity and sensitivity of $66 \%$ [13]. This study is the second one to investigate the usefulness of the BOAH scale among sleep clinic patients. Previously, it was studied among 1135 patients, who underwent PSG examination in Sleep and Respiratory Disorders Centre (Lodz, Poland). In that study, the BOAH scale presented greater predictive values than the STOP-BANG questionnaire at the optimal cut-off points [9]. As the aforementioned center deals exclusively with OSA patients, in the present study, the scale was evaluated in a center attending to various sleep disorders to verify its potential diagnostic value on a more heterogeneous patient group. The BOAH scale disclosed the highest AUC (0.78) for severe OSA, at a cutoff level of 4, high specificity (89\%), PPV (75\%), and NPV (78\%). The BOAH scale has had similar AUC results to NoSAS for clinically significant OSA (compared to both: the original and validating cohort, 0.74 and 0.81 , respectively) [8], while having simpler scoring criteria suggesting it can be used as a robust tool for prioritizing patients with a high risk of severe OSA, for PSG examination. Furthermore, STOP-BANG meta-analysis [13] shows that PPV of $97 \%$ for mild and $88 \%$ for moderate OSA is achieved for a score of 7 in this questionnaire, which directly corresponds to the predictive values obtained for the BOAH score of 4 . This shows that BOAH scale has the same diagnostic values as STOP in mild and moderate OSA diagnoses. Additionally, with 99\% sensitivity, BOAH score of 1 has 97\% NPV for severe OSA with only one false negative, allowing for quick prioritization of patients for PSG examination, while the STOP-BANG for the same severity and sensitivity has NPV of $89 \%$ at the cutoff point of 2 . The primary limitation of the study is the lack of direct comparison between STOP-BANG and BOAH scores in the study group. Unfortunately, less than $10 \%$ of individuals included in the analysis had information regarding their neck circumference, 
which is mandatory for STOP-BANG. This shows that a limited number of parameters in the scale are advantageous as it is more likely that necessary data will be collected. In this manner, it may be more friendly to use GPs assessing OSA risk before referral. Yet, in general, neck circumference is recorded for most patients while they are admitted to the sleep clinic, which might make this missing data a negligible problem. The relatively small size of the study group could be also considered as a limitation to the study. Nevertheless, obtained results for the BOAH scale were comparable to the original study on a larger group of patients [9], which suggests that the examined group was representative.

BOAH scale is a valuable tool in OSA diagnosis and assessment of the risk of the disorder. It offers similar predictive values to other available tools while being shorter and easier in use. Therefore, it should be considered as a useful tool in clinical practice.

Author contribution AG created concept of the study and generated data base. AG and GK wrote the manuscript. $\mathrm{M}$ and $\mathrm{AG}$ was responsible for statistical analysis. All authors were involved in revising the manuscript.

Funding information This study received no funding.

\section{Compliance with ethical standards}

Conflict of interest The authors declare that they have no conflict of interest.

Ethical approval All procedures performed in studies involving human participants were in accordance with the ethical standards of the institutional and/or national research committee and with the 1964 Helsinki declaration and its later amendments or comparable ethical standards.

Informed consent All patients gave written informed consent for diagnostic polysomnography.

Open Access This article is licensed under a Creative Commons Attribution 4.0 International License, which permits use, sharing, adaptation, distribution and reproduction in any medium or format, as long as you give appropriate credit to the original author(s) and the source, provide a link to the Creative Commons licence, and indicate if changes were made. The images or other third party material in this article are included in the article's Creative Commons licence, unless indicated otherwise in a credit line to the material. If material is not included in the article's Creative Commons licence and your intended use is not permitted by statutory regulation or exceeds the permitted use, you will need to obtain permission directly from the copyright holder. To view a copy of this licence, visit http://creativecommons.org/licenses/by/4.0/.

\section{References}

1. Gabryelska A, Łukasik ZM, Makowska JS, Białasiewicz P (2018) Obstructive sleep apnea: from intermittent hypoxia to cardiovascular complications via blood platelets. Front Neurol 9: 635. https://doi.org/10.3389/fneur.2018.00635

2. Mokros Ł, Kuczynski W, Gabryelska A, Franczak Ł, Spałka J, Białasiewicz P (2018) High negative predictive value of normal body mass index for obstructive sleep apnea in the lateral sleeping position. J Clin Sleep Med 14:985-990. https://doi.org/10.5664/ jesm.7166

3. Punjabi NM (2008) The epidemiology of adult obstructive sleep apnea. Proc Am Thorac Soc 5:136-143. https://oi.org/10.1513/ pats.200709-155MG

4. Senaratna CV, Perret JL, Lodge CJ, Lowe AJ, Campbell BE, Matheson MC, Hamilton GS, Dharmage SC (2017) Prevalence of obstructive sleep apnea in the general population: a systematic review. Sleep Med Rev 34:70-81. https://doi.org/10.1016/j.smrv. 2016.07.002

5. Heinzer R, Vat S, Marques-Vidal P, Marti-Soler H, Andries D, Tobback N, Mooser V, Preisig M, Malhotra A, Waeber G, Vollenweider P, Tafti M, Haba-Rubio J (2015) Prevalence of sleep-disordered breathing in the general population: the HypnoLaus study. Lancet Respir Med 3:310-318. https://doi.org/ 10.1016/S2213-2600(15)00043-0

6. Chung F, Yegneswaran B, Liao P, Chung SA, Vairavanathan S, Islam S, Khajehdehi A, Shapiro CM (2008) STOP questionnaire: a tool to screen patients for obstructive sleep apnea. Anesthesiology 108:812-821. https://doi.org/10.1097/ALN.0b013e31816d83e4

7. Chiu H-Y, Chen P-Y, Chuang L-P, Chen NH, Tu YK, Hsieh YJ, Wang YC, Guilleminault C (2017) Diagnostic accuracy of the Berlin questionnaire, STOP-BANG, STOP, and Epworth sleepiness scale in detecting obstructive sleep apnea: a bivariate metaanalysis. Sleep Med Rev 36:57-70. https://doi.org/10.1016/j.smrv. 2016.10.004

8. Marti-Soler H, Hirotsu C, Marques-Vidal P, Vollenweider P, Waeber G, Preisig M, Tafti M, Tufik SB, Bittencourt L, Tufik S, Haba-Rubio J, Heinzer R (2016) The NoSAS score for screening of sleep-disordered breathing: a derivation and validation study. Lancet Respir Med 4:742-748. https://doi.org/10.1016/S22132600(16)30075-3

9. Mokros L, Kuczynski W, Gabryelska A, Bialasiewicz P (2016) BOAH-a shorter version of STOP-BANG questionnaire for prioritizing patients for polysomnography in esleep clinic. ERS international congress 2016 abstracts PA2310. https://doi.org/10.1183/ 13993003.congress-2016.PA2310

10. Gabryelska A, Mokros Ł, Riha R et al (2018) The predictive value of BOAH scale among patients of sleep disorders clinic at the Department of Sleep Medicine in Edinburgh. Porto Biomed. J. YES Meeting (62)

11. Kapur VK, Auckley DH, Chowdhuri S, Kuhlmann DC, Mehra R, Ramar K, Harrod CG (2017) Clinical practice guideline for diagnostic testing for adult obstructive sleep apnea: an American Academy of Sleep Medicine Clinical Practice Guideline. JCSM 13:479-504. https://doi.org/10.5664/jcsm.6506

12. Chung F, Abdullah HR, Liao P (2016) STOP-Bang questionnaire: a practical approach to screen for obstructive sleep apnea. Chest 149: 631-638. https://doi.org/10.1378/chest.15-0903

13. Nagappa M, Liao P, Wong J, Auckley D, Ramachandran SK, Memtsoudis S, Mokhlesi B, Chung F (2015) Validation of the STOP-Bang questionnaire as a screening tool for obstructive sleep apnea among different populations: a systematic review and metaanalysis. PLoS One 10:e143697. https://doi.org/10.1371/journal. pone. 0143697

Publisher's note Springer Nature remains neutral with regard to jurisdictional claims in published maps and institutional affiliations. 